\title{
Integration of Lean method in English Language Teaching and Learning: A New Perspective
}

\author{
Filiz Yalçın Tılfarlıŏglu ${ }^{1}$, Jivan Kamal Anwer ${ }^{2}$ \\ ${ }^{1}$ Department of English Language Teaching, Faculty of Education, University of Gaziantep, Gaziantep, Turkey \\ ${ }^{2}$ Higher School of Foreign Languages, University of Gaziantep, Gaziantep, Turkey \\ Correspondence: Jivan Kamal Anwer, Higher School of Foreign Languages, University of Gaziantep, Gaziantep, \\ Turkey.
}

Received: June 28, 2017

doi:10.11114/jets.v5i9.2625
Accepted: August 22, $2017 \quad$ Online Published: August 27, 2017

URL: https://doi.org/10.11114/jets.v5i9.2625

\begin{abstract}
Lean is regarded as a systematic approach to maximizing value by minimizing waste, and by flowing the product or service at the pull of the customer demand. These key concepts of "value," "flow," and "pull," align with the ultimate lean goal: "perfection," or a continuous striving for improvement in the performance of the organization. Through applying a lean methodology to the teaching processes, additionally the teachers can eliminate reasons that do not add value and are thus wasteful, and they can focus their efforts on the advancement of teaching and learning. By applying the lean principles and techniques developed in the industry, educators can refine the content, pedagogy, organization, and assessment methods employed in their accounting courses to help and ensure that students gain the knowledge and skills that will make them most desirable to students. Lean can be taught throughout several methods and tools, such as readings and class discussion, game- and simulation-based methods, and the open forum method. The readings and discussion method present students with the opportunity, and even the obligation, to express their Point of view on certain issues, requiring the students to think critically on the subject and use logic to evaluate others' positions through open and active participation. When applying lean production to learning, we should first identify the process and then maintain focus on what adds value (i.e., student improvements), empower students to do CI (continuous improvement), eliminate what does not add value through Kaizen (brainstorm alternatives and identify a hypothesis to test), conduct PDCA (develop an experimental plan, carry out the plan or do it and then check for results and adjust accordingly), and make a team work to support and share with each other. To apply lean thinking and to create a lean culture classroom, the classroom should first be organized; thereafter, visual sheets should be managed, pre-planning must be done, take-time should be established, and work should be standardized by creating syllabi and schedules and associated materials. Other classroom tools must be available as well, such as Pareto charts, root cause, and weekly quality assessments. To fulfill this objective, a research question has been approved as a data collection instrument in this descriptive study, a 35 item questionnaire was administered to English preparatory school student at Duhok city and an interview was conducted with twelves students with different levels in Sabis International School. In addition, the descriptive statistics indicated that the male learners employed language learning strategies more frequently (average $=3.3$ ) than the female learners (average $=3.2$ ) One can conclude that male students use lean learning strategies more than female student do. The value of $(\mathrm{F})$ is 2.479 , which reflects the dependency to be at significant levels $(>0.01$ at the level of $1 \%)$. Rendering to this model, duration of taking English $(b=1.534, p=.116 \mathrm{p}>.01)$ is statistically not significant predictor of learning lean method. Value of $\mathrm{T}$ which is $(27.87>.01)$ and the Value of $\mathrm{P}(.000)$ reveals the descriptive factor of gender effect on learning lean method as statistically significant. Besides, all the values in the regression model come out to support the view that gender is effective in the use of learning the lean method. The result also indicates that the duration of taking English does not significantly effect on learning and using lean learning strategies as it reveals in ANOVA analysis. In conclude, the result showed that when student get older and takes more English course, the more learning lean methods they apply in learning language.
\end{abstract}

Keywords: lean, English language teaching, lean strategies, lean methods, academic achievement

\section{Introduction}

The main aim of the study is to describe the lean method and to discover the extent to which it can be integrated into 
English language teaching and learning processes or not and regarding its effects. However, English language teaching has been introduced to a new strategy which may help students as well as foreign language learner to learn language faster. That strategy and concept is called lean production.

The concept of lean is most commonly associated with the Japanese industry, particularly with the Toyota Production System (TPS). Lean production was created in 1950 by a young engineer named Eigi from the Toyoda family; he created the concept after his first visit to the Ford factory (Monden, 1983; Ohon, 1988; Shingo, 1988). It became a powerful tool because of the shortage of resources and intensive domestic competition in the Japanese automobile market. Lean is based on Ford's mass production system that belongs to the United States with some improvements and lies in the development of the hypothesis and data-driven analysis in the scientific method. Henry Ford started one of most substantial revolutions that has ever occurred in the industry, and his efforts are known as the Mass Production System, which was developed in 1908. Henry Ford authorized people to improve the processes they performed.

Over the next two decades, however, lean manufacturing became increasingly popular among Western companies and has been applied not just by different manufacturing organizations but, in some cases, by their service counterparts as well. Lean has now been applied across a wide range of industrial settings and "has moved away from a merely 'shop floor-focus' on waste and cost reduction to an approach that contingently sought to enhance value (or perceived value) to customers by adding product or service features and/or removing wasteful activities" (Hines et al., 2004: 995). Lean delivers the most value from the customer's perspective while consuming the fewest resources. The steady growth of Toyota, from its start as a small company to becoming one of the world's largest automakers, has focused attention on how its success was achieved. The supporters of lean argue that lean manufacturing has greatly improved production efficiency. Toyota recognizes the implications and applies the collective genius of these predecessors to its small manufacturing operation. It then refines and expands its process-improvement-through-waste-elimination focus to include the enterprise-wide operations (Ziskovsky, 2007).

Lean is also perceived as being a set of tools or techniques that allow for the reduction of waste. There are five principles to guide the implementation of lean techniques. Moreover, lean consists of 25 tools: $5 \mathrm{~S}$ "reduce wasted time and motion at the micro level", autonomation (allows automated equipment to operate without human intervention or monitoring); cellular manufacturing (simplifies the workflow and concentrates on a single product or narrow family; improves quality, inventory, and many other parameters), continuous flow (coordinates production by ensuring synchronized, continuous flow throughout the value stream), continuous improvement (to institutionalize the practice of making many small improvements every day and improve overall efficiency such as with compound interest); Design for Six Sigma (DFSS) (to ensure that a product's design is easy to manufacture without defects and meets customer needs.), elimination of waste (improve efficiency and effectiveness.), focused factories (align process capabilities with marketing strategy and concentrate expertise); in-station quality control (prevents defects from passing to downstream processes and ensures immediate feedback for correction of quality problems); jidoka (prevents problems on one station of a production line from building inventory and also creates urgency to find permanent solutions); Six Sigma (improves quality, operational performance, practices, and systems.), Kaizen Blitz (improves localized production areas quickly and dramatically overcomes inertia common to many organizations); Kanban schedule production and minimize work-in-process while encouraging improvement in many areas. lean accounting means to properly account for lean activities and support the lean initiative; lean office is mean to carry lean principles to activities normally done in an office environment; lean suppliers usually push improvements upstream in the supply chain; manufacturing strategy is to ensure a match, or congruence, between the company's markets and production system capability; mixed model production is a steadies the demand on production processes upstream from a final assembly line; one-piece flow means to reduces inventory internal to a work cell and forces improvements and work balance; point-of-use storage is to reduces material movement; process mapping is to visualize and understand the sequence and nature of events in a process at the macro and micro levels; production leveling is steadies demand variability on processes; Pull and synchronous scheduling means to closely link and synchronize processes and prevent surges of WIP inventory and/or shortages; quick and easy Kaizen work is to formalize, spread, and maintain continuous improvement activities; and setup reduction means to minimize setup time and cost, thereby freeing capacity and enabling the production of very small lots.

Lean includes Kaizen (Japanese for "change for the better" or "improvement", the English translation is "continuous improvement", or "continual improvement."), a strategy where employees at all levels of a company work together proactively to achieve regular, incremental improvements to the manufacturing process. In a sense, it combines the collective talents within a company to create a powerful engine for improvement-it is part action plan and part philosophy. Kaizen is a daily activity whose purpose goes beyond improvement. It is also a process that, when done correctly, humanizes the workplace, eliminates hard work (both mental and physical), and teaches people how to do rapid experiments using the scientific method and how to learn to see and eliminate waste in business processes. As an 
action plan, Kaizen is about organizing events focused on improving specific areas within the company. These events involve teams of employees at all levels, with an especially strong emphasis on involving plant floor employees. As a philosophy, Kaizen is about building a culture where all employees are actively engaged in suggesting and implementing improvements to the company. In truly lean companies, it becomes a natural way of thinking for both managers and plant floor employees.

Lean also includes poka-yoke which refers to mistake-proofing (also error-proofing or fool-proofing). These are creative devices that make it nearly impossible for an operator to make an error. (Liker, 2004). Poka-yoke have five ways and mistake proofing that was developed by Shigeo Shingo from Toyota Motors as a tool to achieve Zero Defects. The process of Zero Defects (ZD) is also known as "mistake proofing" or "fail-safe." By taking over repetitive tasks or actions that depend on vigilance or memory, poka-yoke can free workers' time and their minds to pursue more value-added activities. As an example, though they did not have a poka-yoke to check if the cotter pin was in place, they did have a light curtain over the tray of cotter pins. If the light curtain was not broken by the operator reaching through it to pick up a cotter pin, the moving assembly line would stop, and Andon light would come on, and an alarm would sound.

Lean production has five principle and seven wastes, and with the help of these tools wastes can be reduced and eliminated. Lean production means creating more value for customers with fewer resources, which means exploiting customers' values while reducing waste. Lean is comprised of qualified people who continuously search for the simplest and smoothest process in order to fully meet customers' needs. To be 'lean' is to adopt a philosophical strategy that is relentless in its effort to create value for the customer through the elimination and prevention of waste, such as excess inventory, needless motion, and other time- and resource-consuming activities. Essentially, lean aims to create a value stream that is comprised of only the processes that add perceived customer value; everything else is unnecessary and should be disregarded. As more value is created with fewer resources, lean operations can increasingly focus on allowing customer demand to pull products and services through production and the supply chain. However, unless stability and optimal flow exist, the lean value stream cannot meet the demand that is pulled through the system without using a considerable buffer inventory (Glovia International, Inc., 2008).

Lean is a program of organizational improvement that empower each and every worker in a school system (from student through superintendent) to increase her/his personal performance and job satisfaction through process improvement. Lean engage everyone in a streamlining his or her work processes by identifying and eliminating the step within each process that are wasteful, unnecessary or do not contribute the value to work. By incorporating a value-adding approach system-wide, schools can be more efficient in their operation and more effective at deliver their services, optimize the learning performance of all students, and create a culture of success and satisfaction for all(Ziskovisky, 2011,).

Lean is still a relatively new approach to Higher Education reform. Only during the last 5-8 years universities and colleges began to experiment with Lean principles. The overwhelming majority of cases covered in the literature are from the US where most HEIs always operated in a competitive market environment and thus are more open to private sector management practices (Owlia \& Aspinwall 1997). However, the quality of this literature is rather poor. Most of it falls under the category of grey literature, e.g. several online papers with rather anecdotal evidence (Moore et al. n.d.; Alp n.d.; Kusler n.d., see also Jin \& Kachroo 2010). In these accounts, which do not meet academic standards of empirical research, the authors praise the success of their own Lean projects but remain very vague with regards to the applied Lean approach and the quantitative outcomes. One conference paper (Barroso et al. 2010) and a monograph (Balzer 2010) do only summarizes these accounts in a rather uncritical and naïve manner without making their own investigations. The few scholarly articles on the topic remain purely theoretical (Dahlgaard \& Østergaard 2000) or put every type of reform activity in HE under the Lean heading (Comm \& Mathaisel 2005a, 2005b) - again an example of ex-post rationalization.

Through lean thinking programs, many universities have experienced comprehensive process improvements and cost reductions. Lean's origins are from industry, not academia, but lean management can be successfully applied to HE organizations. The impact of lean in HE has been studied and found to be potentially beneficial. Reports analyzing lean in higher education have indicated that lean principles are being successfully applied. The lean methodology has become more common in higher education institutions to reduce waste, streamline processes, and re-engage a workforce fatigued from the effects of the 2008 financial crisis (Balzer, 2010; Finn \& Geraci, 2012; Radnor \& Bucci, 2011). Universities and colleges are seeking greater efficiency in their academic programs and service delivery areas and are making decisions to prioritize key areas (Dickeson, 2011). Universities and colleges operate in a climate of uncertainty and face an increased scope of the mission, unstable enrollments, costs that are outpacing inflation, and diminished government support (Association of Universities and Colleges in Canada, 2012). Further, Houston (2008) posited that higher education has moved from a model focused on accountability to one focused on improvement, and lean methodology is increasingly seen as a central strategy for improvement.

Lean Teaching is a practical guide for college and university professors who are interested in becoming better teachers. 
Lean is about learning respect for people because, without engagement, there is no learning and continual improvement that necessarily involves learning, nor are there shifts in thinking that enable us to see things differently. An organized environment helps children to be more independent and helps teachers spend more time on their students rather than spending time searching to find what is needed. Most startups fail because they waste too much time and money building the wrong product before realizing too late what the right product should have been. As such, teachers should introduce students to the idea of the lean startup - a methodology that has proven successful for many young high-tech companies (Eisenmann, 2011).

Lean is a philosophy of continuously simplifying processes and eliminating waste. Its uses are simple, and it offers easy-to-understand tools that can be applied in any organizational setting. Drawing on the creative thinking of employees, an organization can apply lean principles without huge capital expenditures. Organizations applying lean principles encounter significant results, such as increases in productivity, decreases in defects, reductions in inventory, and improved on-time deliveries and cash flows (Tatikonda, 2007).

Teaching complicated concepts such as lean philosophy to students or employees who have never had any contact with it may be a quite challenging task. The challenge, when teaching students, is to create a context so that they can imagine and understand why lean philosophy is important and how it can work. The challenge is to create an experience with all of the relevant technical as well as social concepts such as pull production, cycle time, work-in-progress, balancing, teamwork, and communication (Dukovska-Popovska, 2014).

While lean process improvement is a relatively new concept for the education industry as a whole, some forward thinking educators have applied this powerful approach specifically to discover ways to improve student learning. The results of these pioneering efforts to identify and eliminate waste in the teaching and learning processes are consistent with the results experienced by other lean organizations - improved performance with cost savings (Zikovisky, 2007).

Lean can be taught throughout several methods and tools, such as readings and class discussion, game- and simulation-based methods, and the open forum method. The readings and discussion method presents students with the opportunity, and even the obligation, to express their Point of view on certain issues, requiring the students to think critically on the subject and use logic to evaluate others' positions through open and active participation. Some of the benefits of using readings and discussion as a learning method, are that it helps students to explore and analyze a variety of perspectives, it increases their intellectual quickness and teamwork habits; it develops students' combination and integration skills, and it leads to transformation (Bonwell \& Eison, 1991).

The open classroom forum is a dynamic teaching method in which students interactively share thoughts and learn from class discussions about case studies and required readings. The purpose of an open classroom forum is to establish a new pedagogy for teaching lean (Hamzeh, 2013). This method is applied in the Construction Management Department of Colorado State University, and the lecturers are expected to facilitate the understanding of lean principles while "preparing students to enter the workforce with a solid theoretical understanding of lean and its transferability to the construction operating platform" (Hamzeh, 2013). As an evolution of the open classroom forum method, the online discussions forums method comes across as the most preferred by students. Tsao et al. Post questions to a discussion that weave several strands of conversation into a summary that may prompt people to pursue the topic further or even seek help when necessary. Lean implementation on schools has two main point: first Increase the learning output for the pupils which Provide pupils with more time for learning, teachers with more time for teaching, and increase the quality of teaching, Second Improve the working environment for the teachers to Create a more attractive working environment at the school and remove "time thieves" in administration of classes (T. Netland, 2005).

Lean can be used by schools to examine processes for improvement ranging from the core technology of delivery of instruction to administrative support. For instance, value stream mapping (Keyte \& Locher, 2004) is a lean tool that can be used to solicit the views of key stakeholders, such as students, teachers, parents, policy makers, administrators and boards, in regard to what is of value in the instructional delivery process. A student's instructional day can be mapped out looking at allocations of time and resources for various activities. Based on the views of key stakeholders, decisions would be made as to what is of value during that instructional day and what is not. What is of value is kept and what is not is either improved so that it becomes valuable or it is eliminated (Flumerfelt, S., \& Green, G., 2013).

\section{Methods}

\subsection{Participant}

There were (622) participants from total (622) in the study from all levels in the (Sabis International School) in the academic year of 2016-2017. The sampling is the whole research population, totally 282 female and 340 male students attended to the research and the age of student were between (5-15) years old and their background of English language were concerted between three groups (0-5, 5-10, 10-15) years of learning English . 


\section{Measures}

To investigate the correlation between lean learning strategies and the duration of taking English course, and regression analysis of the relationship between a gender and the use of lean learning strategies, quantitative descriptive research analysis was applied.

After setting research topic, the research design is defined and a pilot study is applied, so that the reliability of the instruments can be proved

A 35-item questionnaire about lean production has been conducted to 622 participant out of 622 at Sabis International School in Duhok city. A 5 choice Likert type of questionnaire was developed in order to assess the subject levels of agreement or disagreement in a quantifiable manner, ranging from "never" to "always was used in the questionnaire. Point five was referred to "always" while four points was labeled as "usually". Three points was defined as "sometimes" and two points as "rarely". Lastly, one point was qualified as "never". To investigate the relationship correlation research design by Pearson-Correlation style was applied.

\section{Finding}

Applied questionnaires were collected. All data analyses were carried out using the Statistical Package for Social Sciences (SPSS). The Split-half technique was used to measure the reliability of the questionnaire. The Split-half reliability coefficient was calculated to be 0,80 which were defined to be reliable for Likert-type attitude. The data was analyzed by using frequencies, percentages, mean, correlation, linear regression, and ANOVA. The frequency and the percentage of the male participant in the data is (340), (54.7) while the frequency and the percentage of female participant is (282), (45.3). Besides, the frequency and percentage of the participant who take (1-5) years is (182), (29.2), (5-10) years is (219), (35.2), (10-15) years is (221), (35.5). The data showed that the student of Sbis International School in Duhok city can use lean learning strategies, in sum the results indicated that the use of the strategies by overall students stays within the scope of high frequency (3.5-5.0) and moderate use (2.5-3.4). So, according to the results, there was not low frequent use of any of the strategies (1.0-2.4). In addition, the overall average reported frequency of strategy use was 3.2. Moreover, the descriptive statistics indicated that the male learners employed language learning strategies more frequently (average $=3.3$ ) than the female learners (average $=3.2$ ). One can conclude that male students use lean learning strategies more than female student do. As the second step, the correlation between lean learning strategies and the duration of taking English course was put forth. As an answer to each research question the Pearson product-moment correlation co-efficient, ANOVA and linear regression was computed between the variables was studied. The value of $(\mathrm{F})$ is 2.479 , which reflects the dependency to be at significant levels ( $>0.01$ at the level of $1 \%)$. Rendering to this model, duration of taking English $(b=1.534, p=.116 \mathrm{p}>.01)$ is statistically not significant predictor of learning lean method. Value of $\mathrm{T}$ which is (27.87> .01) and the Value of $\mathrm{P}(.000)$ reveals the descriptive factor of gender effect on learning lean method as statistically significant.

Table 1. Correlations between lean learning strategies and the duration of taking English course

\begin{tabular}{|c|c|c|c|}
\hline \multicolumn{4}{|l|}{ Correlations } \\
\hline & & Gender & $\begin{array}{l}\text { Duration of taking } \\
\text { English }\end{array}$ \\
\hline Gender & $\begin{array}{l}\text { Pearson correlation } \\
\text { Sig. (2-tailed) }\end{array}$ & 1 & $\begin{array}{l}-.063- \\
.116\end{array}$ \\
\hline & $\mathrm{N}$ & 622 & 622 \\
\hline $\begin{array}{l}\text { Duration of } \\
\text { Taking English }\end{array}$ & $\begin{array}{l}\text { Pearson correlation } \\
\text { Sig. (2-tailed) } \\
\text { N }\end{array}$ & $\begin{array}{l}-.063- \\
.116 \\
622\end{array}$ & 622 \\
\hline
\end{tabular}

The results, indicated that there was a significant negative correlation between reported frequency of lean learning strategy use and gender, duration of taking English $(r=-.063, \mathrm{p}=116 p>0.01, \mathrm{n}=622)$ which is good. This means that There is a negative correlation between duration of taking English course and lean learning strategies because sig. (2-tailed) $=0.116$ which is greater than 0.01 , which mean that there is a negative relationship between gender and the duration of taking English course. Thus, there is not sufficient evidence to state that this correlation exists in the population. 
Table 2. The regression analysis of the relationship between a gender and the use of lean learning strategies

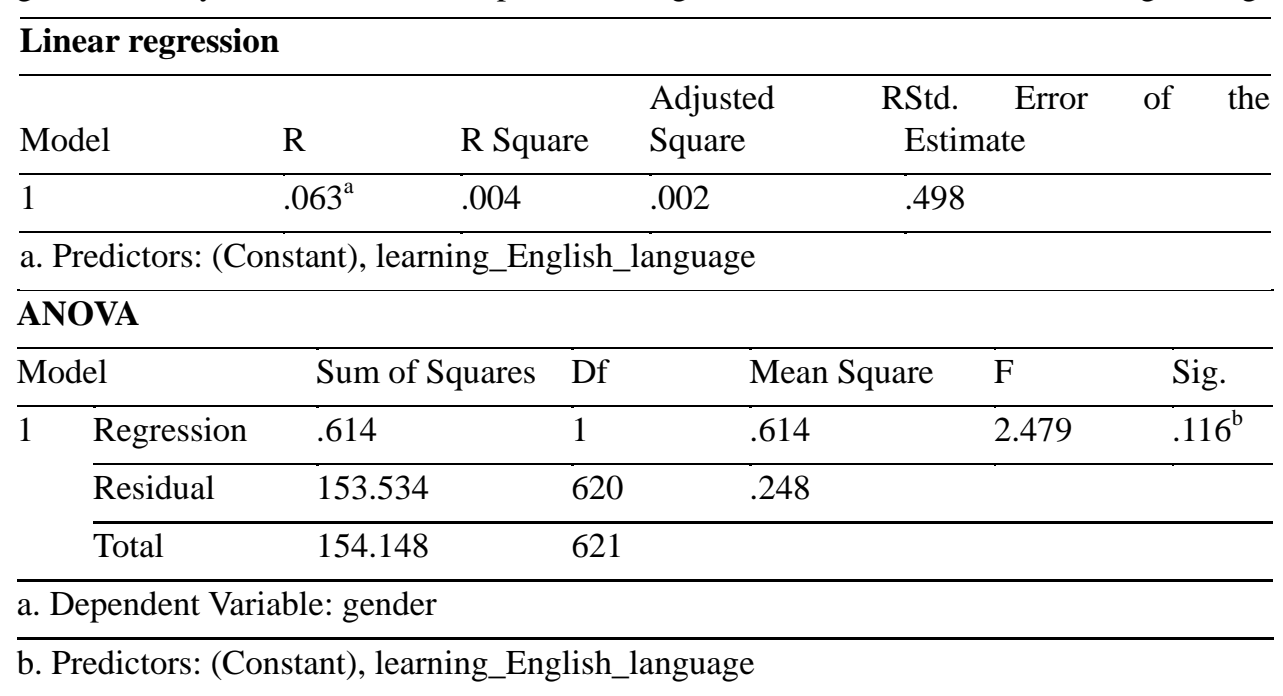

In order to observe if the regression model is meaningful or not, ANOVA was conducted. According to ANOVA, duration of taking English $(r=-.063, p=.116 p>.01)$, the value of $(F)=2.479$, is statistically not significant predictor of learning lean method. While, the Value of $\mathrm{T}$ which is (27.87.01) and the value of $\mathrm{p}$ is (.000) reveals the descriptive factor of gender effect on learning lean method as statistically significant. In addition, all the values in the regression model come out to support the view that gender is effective in the use of learning the lean method. Among other factors, such as gender, age, duration of taking English course also explains the difference at adopting learning lean method. It means that the gender effect on choosing learning lean methods and then applying it in language learning while the duration of taking English course does not effect on lean learning strategy.

\section{Conclusion}

Lean Management is not a new concept, but it is new for the Education. There is no question that differences exist between the products of a manufacturing assembly line and those of an education service. However, a huge similarity exists in the delivery systems of these organizations, delivery systems made up of thousands of complex processes. As such, many aspects of Toyota's process improvement methodologies and other Lean tools can and do apply to improving the processes of delivering education (Ziskovsky, 2007).

In addition, lean is a new method of production and a new way to organize the whole innovativeness, including the development of new products. A lean organization allows students to create products not only faster and cheaper, but better because they provide more value to students. Lean innovation allow students to create instructions for learning, the objectives are stated clearly to students so they know what to expect, the whole course is planned out before, so there is a standard in each course, students study at their own pace, the information is available online and easy to access, students have better understanding with unit-perfection requirement for advance. The core principle of lean is that every process should add value, as value is defined by the student. Every step that does not add value, known in Lean as waste, should be eliminated to the extent possible.

In sum, innovation is a process in which ideas are translated into new products and processes to create, improve, or expand business opportunities, on the other hands when we look at the foundations of Lean we will see that lean provide students some important insights, for example, what can students learn from doing kaizen effectively that can help them to develop new products, processes and improve existing ones. Lean is one of the most important organizational innovations of the recent management history and a leading force to stimulate the innovation process within existing establishments as well as startups. Lean necessities, basic assumptions, practices, and tools have the potential to transform an establishment into an organism of knowledge, ideas, and innovations generation. Lean has always been more than just an improvement method.

The main finding of this article is that there is not a high statistical significant difference between the duration of taking English course and using lean learning strategies but there is a high statistical significant relationship between gender and using lean learning strategies.

This research demonstrates that there is a negative correlation of the data which mean that there is no significant different between the duration of taking English courses that the students has taken, in using the overall use of lean strategies by (mean: 9.84). As it has been mentioned the main aim of the study is to revel to what extent does lean can be integrated into English language teaching in addition to examine its effects and according to the result of the data 
lean can be integrated into English learning process $50 \%$ which indicated positive outcomes and there is a chance that lean can be a good process for education system in the future.

It has been proven by many researchers such as Betty Ziskovsky in 2010 that after applying lean methods and principles on schools, student's data prove the methodology for success, their learning performance improved, restored interest for learning and long term improvement in self-assurance and personal accomplishment. Although this study was conducted in one region, the results should be take a broad view to other areas. The findings suggest that this approach would also be beneficial in other sectors.

Generally there is a misperception that lean practices can be effectively implemented only in the manufacturing sector. But this research reveals that that lean practices can be successfully implemented in education sector also leading to proven beneficial financial results and excellent students satisfactions. Lean is not only restricted to the tools but also it embraces the involvement of an active students. Through distinct approaches, many proposals have been made to improve the workflow through the application of lean methodologies to remove the non-value added activities. Lean practice needs a reengineering heart and motivation on the part of organization to use lean to its full potential to obtain good returns economically as well as satisfactorily.

Lean method is a promising approach to improve productivity in the road creation sector. Lean principles have been successfully applied to optimize the processes in companies and projects. Training is a relevant part of sustainably implementing lean method. Simulation games are very suitable to impart lean principles and prove to be an important supplemental tool for teaching. Successful second language learners are aware of the strategies they use and why they use them. They are capable of using these strategies for the given tasks and for their personal needs as learner, while learning a second language. The contribution of this study to language teachers or researchers can be the finding related with the students preference about learning English language. In addition, we got to conclude that the student who suffer at the hands of the shortcoming of our current educational system, lean could be extremely helpful, which mean that Lean method is appropriate for school but it has to be understood as a system and implemented with clarity. Lean help academicians in better understanding student's needs, selecting and organizing course topics and activities, changing teaching pedagogy, making realistic assessments of student learning. In an environment of rising education system, application of lean principles reduces wastes and adds more value without requiring huge work. Drawing on the intelligence of individuals, Lean applications show highly significant results in productivity, cost, and school.

\section{Recommendation}

Successful second language learners are conscious of the strategies they use. They are capable of using these strategies for the given tasks and for their personal needs as learner, while learning second language. Since the result of this study is satisfied with quite good number of participants, it recommended that this research should be conducted in a larger scale with different universities in various cities or distinct groups of participants since what is required is to be able to make more significant generalizations and beneficial confirmations on the results. Besides, since learning lean strategies are directly connected with English achievement, some courses aiming to make students acquire better learning strategies could be prepared with the target of improving language learning skills. It is important for the students and teachers to have knowledge about the learning styles and learning lean strategies in the language learning process. For instance, it would be effective to include required or influential learning lean strategies while teaching subjects or principles in each discipline. It would certainly make contributions on the students' academic success. And, also the instructors of these strategies are to be educated in teaching and assessing issues. Actually, at the very beginning, while setting a goal students are to determine strategical approaches, adapt them and arrange new strategies. Throughout the process, views of the learners and teachers have to be gotten as to assess the suitability of the strategies.

Universities and colleges have unique capacities for producing original research and are incented to produce it in timely, rigorous ways that many other organizations would find difficult to match. The prospects for new research programs concerning the use of Lean in higher education are strong; such programs would help not only ensure business continuity in the higher education sector but new linkages with worldwide institutions in education and industry(David E.2014).

The management must decide to work with Lean strategy and methods and give the initial knowledge and skills to the co-workers so they can start testing working with Lean tools. The management needs to be prepared to design a common and visual system of working with Lean together with the co-workers in order to create a common understanding of the organization. The co-worker must be prepared and really motivated to work according to Lean principles and the management must support and encourage the co-workers in that. As the Lean tools and the common system of working with Lean is developed the management must both support and encourage the co-workers but they must also ask for results to keep the process ongoing and alive (Lean Vet. 2017).

As a result of the improvement made, it will be ensured that the information on the deficient lessons and subjects of all 
students, the current states of students and their development can be followed better, that the opinions of students about études and the teacher will be obtained, that the études performance of teachers will be evaluated, that the unnecessary inventories resulting from the unplanned use of documents like tests will be eliminated, and that quality and hence success will be increased.

\section{References}

Balzer, W. K. (2010). Lean higher education: Increasing the value and performance of university processes. New York: Productivity. https://doi.org/10.1201/EBK1439814659

Bonwell, C., \& Eison, J. (1991). Active learning: Creating excitement in the classroom (ASHE-ERIC Higher Education Report No. 1). Washington, DC: George Washington University.

Dahlgaard, J. J., \& Østergaard, P. (2000). TQM and lean thinking in higher education" in M.N. Sinha, ed., The Best on Quality: Targets, Improvements, Systems, Volume 11 of International Academy for Quality Book Series, Milwaukee, 203-226.

David, E. F. (2014). Lean and the learning organization in higher education. Canadian Journal of Educational Administration and Policy, Issue \#157, April 28, 2014

Dukovska-Popovska, V., Hove-Madsen, \& Nielsen, K. B. (2014). Teaching lean thinking through game: some challenges, Aalborg University, Department of Production, DK-9220 Aalborg, Denmark Education. Retrieved from https://youtu.be/MtC4WToqVv0

Eisenmann, T., Ries, E., \& Dillard, S. (2011). Hypothesis-driven Entrepreneurship: the lean startup Harvard Business School Background Note 812-095

Flumerfelt, S., \& Green, G. (2013). Using Lean in the Flipped Classroom for At Risk Students. Educational Technology \& Society, 16(1), 356-366.

Hines, P., Holweg, M., \& Rich, N. (2004). 'Learning to evolve: A review of contemporary lean thinking, International Journal of Operations \& Production Management, 24(10), 994-1011. https://doi.org/10.1108/01443570410558049

Keyte, B., \& Locher, D. (2004). The complete lean enterprise: Value stream mapping for administrative and office processes. New York, NY: Productivity Press. https://doi.org/10.1201/b16650

LeanVet. (n.d.). Retrieved Jan20, 2017, from http://www.leanvet.eu/

Monden, Y. (1983). The Toyota Production System, Productivity Press

Netland, T. (2017). Lean in the primary school? Better operations Norwegian October 8, 2015, Web.

Ohon, T. (1988). The Toyota Production System: Beyond Large-Scale Production, Productivity Press, OR.

Shingo, S. (1988). Non-Stock Production: The Shingo System for Continuous.

Tatikonda, M. V. (2007). Product development performance measurement. In: Loch, C., Kavadias, S. (Eds.), The Handbook of New Product Development. Elsevier Publishers, Oxford, United Kingdom

Tsao, C., Azambuja, M., Hamzeh, F., Menches, C., \& Rybkowski, Z. (2013). Teaching lean construction - perspectives on theory and practice. Proceedings IGLC-21, 977-986. Fortaleza, Brazil.

Ziskovsky, B., \& Ziskovsky, J. (2007). Doing more with less-Going lean in education. Lean education enterprises.

Zivkosky, B. M., \& Zivkosky, J. (2007). Applying process improvement to K-12 education [Whitepaper]. Cambridge, MA: Lean Enterprise Education. http://www.glovia.com

\section{Copyrights}

Copyright for this article is retained by the author(s), with first publication rights granted to the journal.

This is an open-access article distributed under the terms and conditions of the Creative Commons Attribution license which permits unrestricted use, distribution, and reproduction in any medium, provided the original work is properly cited. 